11. Wijeratne, T. L., De Costa, W. A. J. M. and Wijeratne, M. A., Carbon sequestration potential of tea plantations in Sri Lanka. In Conference paper 228th Experiment and Extension Forum, Colombo, Sri Lanka, 2014.

12. Li, S. et al., Quantifying carbon storage for tea plantations in China Agric. Ecosyst. Environ., 2011, 141, 390-398.

13. Kamau, D. M., Spiertz, J. H. J. and Oenema, O., Carbon and nutrient stocks of tea plantations differing in age, genotype and plant population density. Plant Soil, 2008, 307, 29-39.

14. Kalita, R. M., Carbon storage and sequestration in tea agroforestry system in Barak Valley, Assam. Ph D thesis, Assam University, Silchar, 2015.

15. Singh, S. and Dadhwal, V. K., Vegetation Carbon Pool Assessment of India, Indian Institute of Remote Sensing, Dehradun, 2009.

16. Mayer, H. D. G., A manual and tutorial for the proper use of an increment borer. Tree Ring Res., 2003, 59, 63-79.

17. FRI, Indian Woods, Volume I-VI, Forest Research Institute, Dehradun, 1996.

18. Zanne, A. E. et al., Global Wood Density Database, Dryad, 2009; http://hdl.handle.net/10255/dryad.235.

19. FSI, Volume Equations for Forests of India, Nepal and Bhutan, Forest Survey of India, Dehradun, 1996.

20. Devagiri, G. M. et al., Assessment of above ground biomass and carbon pool in different vegetation types of south western part of Karnataka, India using spectral modeling. Trop. Ecol., 2013, 54, 149-165.

21. Ravindranath, N. H. and Ostwald, M., Carbon Inventory Methods Handbook for Greenhouse Gas Inventory, Carbon Mitigation and Roundwood Production Projects, Springer, The Netherlands, 2008.

22. IPCC, Intergovernmental Panel on Climate Change 2007. Synthesis Report, 2007; http://www.ipcc.ch/pdf/assessment-report/ar4/ syr/ar4 syr.pdf (accessed on 10 May 2011).

23. Kalita, R. M., Das, A. K. and Nath, A. J., Allometric equations for estimating above and belowground biomass in tea (Camellia sinensis (L.) O. Kuntze) agroforestry system of Barak Valley, Assam, Northeast India. Biomass Bioenerg., 2015, 83, 42-49.

24. Newbould, P. J., Methods for Estimating the Primary Production of Forests, IBP Handbook No. 2. Blackwell Scientific Publications, Oxford, 1967, p. 62.

25. Velmurugan, A., Kumar, S., Kudrat, M. and Dadhwal, V. K., Spatial Assessment of Soil Carbon Pool of India, Indian Institute of Remote Sensing, Dehradun, 2009.

26. Bouyoucos, G. H., Hydrometer method improved for making particle size analyses of soils. Agron. J., 1962, 54, 464-465.

27. Brady, N. C. and Weil, R. R., The Nature and Properties of Soils, Pearson Education, New Jersey, 2008, 14th edn.

28. Chan, K. Y., Bowman, A. and Oates, A., Oxidizable organic carbon fractions and soil quality changes in an oxicpaleustalf under different pasture leys. Soil Sci., 2001, 166, 61-67.

ACKNOWLEDGEMENTS. We thank the Council of Scientific and Industrial Research, New Delhi for financial support (Scheme number: 38(1349)/13/EMR-II dt.14.02.2013) to undertake this study. We also thank the Tea Research Association Cachar Advisory Centre for providing meteorology data, and smallholder tea growers for permission to carry out research in their plantations.

Received 3 August 2016; accepted 29 November 2017

doi: $10.18520 / \mathrm{cs} / \mathrm{v} 116 / \mathrm{i} 9 / 1560-1566$

\section{Phylogenomic analysis and gene organization of mitogenome from Mong Cai pig in Vietnam}

\author{
Thuy Thi Bich Vo ${ }^{1, *}$, Hieu Duc Nguyen ${ }^{1}$, \\ Tuan Anh Bui ${ }^{2}$, Binh Thi Nguyen Le ${ }^{1}$, \\ Minh Ngoc Nghiem ${ }^{1}$ and Hai Van Nong ${ }^{1}$
}

${ }^{1}$ Institute of Genome Research, Vietnam Academy of Science and Technology, Hanoi 1000000, Vietnam

${ }^{2}$ Institute of Forensic Science, 99, Nguyen Tuan, Thanh Xuan, Hanoi 100000, Vietnam

Mong Cai pig (Sus scrofa) is the Vietnamese indigenous pig breed. The complete mitogenome of this breed has been sequenced and characterized. It is deposited in GenBank with accession number KX147100. There were 37 genes (13 protein-coding, 2 rRNA, 22 tRNA genes and a control (D loop) region) located in 16,711 bp of complete mitogenome. The phylogenetic relationships of both mitogenome and $D$ loop region revealed the shortest genetic distance with Lantang pig breeds and close relationship to some other pig breeds in China regions. Taken together, the valuable data provide essential information for genetic and phylogenetic studies in Vietnamese indigenous animal.

Keywords: Genetic distance, mitochondrial-genome, Mong Cai pig, phylogenetic relationships.

VIETNAM has twenty native breeds of pigs and most of them have been recognized as must conserve livestock gene sources of Vietnam ${ }^{1}$. The Mong Cai pigs are one among them and largely distributed in the provinces of the Northern region, and the northern part of the Central Coastline in Vietnam. They are known for high fertility, withstand low-nutrient food, hot climate condition and resistance to infectious diseases. In the 70's years of the last century, the Mong Cai pig breeds were popular in the northern area, but their population size has reduced now because of the replacement with high growth foreign pig breeds. Thus there is risk of disappearance of Mong Cai pig breed in the livestock map. The excellent indigenous genetic resources should be conserved and protected to effectively use these animal gene resources and contribute to the restoration plan.

Owing to the advantages of molecular methods, one of these methods, mitochondrial (mt) DNA polymorphism has become a useful tool to determine and understand many aspects of animal origin and the dispersal of animal species in the world ${ }^{2,3}$. In addition, the variability of the control region is considered to be important as it may show the phylogenetic events in the past and is used to analyse genetic distances among breeds ${ }^{4}$. Thus the alterations in the non-coding control region sequence used for

*For correspondence. (e-mail: thuytbvo@igr.ac.vn) 
RESEARCH COMMUNICATIONS

Table 1. The sequences of primer pairs used for the amplification of mtDNA fragments from Mong Cai pig

\begin{tabular}{|c|c|c|c|c|}
\hline \multirow[b]{2}{*}{ Primer no. } & \multicolumn{2}{|c|}{ Primers sequences } & \multirow{2}{*}{$\begin{array}{c}\text { Annealing } \\
\text { temperature }\left({ }^{\circ} \mathrm{C}\right)\end{array}$} & \multirow{2}{*}{$\begin{array}{l}\text { Size of PCR } \\
\text { product (bp) }\end{array}$} \\
\hline & Forward sequence & Reverse sequence & & \\
\hline D-loop & AGGAGACTAACTCCGCCAT & GCGGATACTTGCATGTGT & 54 & 1243 \\
\hline 2 & ACTAAGTCAATGCCTATTCTG & CAAATGTATGAAACCTCAG & 54 & 871 \\
\hline 3 & CTACACAATAACCTCCCATA & TGGCACGAGATTTACCAACT & 54 & 383 \\
\hline 4 & GCTCATAACGCCTTGCTC & АТТСТТТСАТСТТТСССТТ & 54 & 1037 \\
\hline 6 & CCGTAAGGGAAAGATGAAAG & TATGGTTATTTTGACTGGT & 54 & 1099 \\
\hline 7 & CCGTGCAAAGGTAGCATA & CCAACATCGAGGTCGTAA & 55 & 417 \\
\hline 8 & TGGGGTGACCTCGGAGTAC & AATATGGCGAAAGGTCCGG & 54 & 1166 \\
\hline 9 & CGAGCAGTAGCCCAAACA & GGTCGTATCGGAATCGTG & 55 & 450 \\
\hline 10 & GTATCAGGCTTTAACGTAGA & TGGTAATACTGCTGTCATTC & 54 & 1128 \\
\hline 11 & CACAGAAGCAGCCACAAA & ATGGGATAGGGATAAAGT & 55 & 540 \\
\hline 12 & ACATAGGATGAATGACAGC & TGGTGGAAGTAGTCAGAAAC & 55 & 1194 \\
\hline 14 & CCCATTATGATTGGGGGTTT & TGCTGTGTATGCGTCAGGAT & 55 & 1134 \\
\hline 15 & CACTTTGTAATCATATTCGTAG & TAGTTGGAAAGGGTAAGC & 53 & 481 \\
\hline 16 & TTCATCTCACTAACAGCAG & TTGAGTTCGGTTGATTCTG & 55 & 1200 \\
\hline 17 & GCTTCATGCCCATTGTAC & TTATAGCGGAATCCTGTG & 55 & 662 \\
\hline 18 & GCAAGCCCAGAATCAACCG & CGAGGAGGATTGAGGTGTT & 55 & 1153 \\
\hline 19 & ATACCACATAGTAAACCCAA & CCTGTAGCCACAAAGAAA & 55 & 584 \\
\hline 20 & СТАААСАССТСААТССТСС & TTGGACGTAATCGGTACCG & 55 & 1151 \\
\hline 21 & CCTTGCAGGGTTACTTAT & TTCGGGTTGTGGTTTCTT & 53 & 519 \\
\hline 22 & CGGTACCGATTACGTCCAA & CCGATTAGATTGATGGATG & 55 & 1165 \\
\hline 23 & ACCAGCTCTATCTGCTTA & GAGGCTTTGATGTTGTTA & 55 & 472 \\
\hline 24 & ATGATGACTAATAGCAAGCC & GGGATGTAGTCCGAATTG & 55 & 1198 \\
\hline 25 & CATCGGAGACATTGGATT & AGTTGGCTTGAAGTTGAG & 53 & 401 \\
\hline 26 & ССТАСТССТАGCTGCAGCAG & ATTATGGAGATTACTCGTGG & 55 & 1186 \\
\hline 27 & TCCGCATCATCATTACTA & TTTATGGTGGACTTGGGT & 55 & 611 \\
\hline 28 & TAATTACCACGAGTAATCTC & TTCTACGAGGTCTGTTCCG & 55 & 1093 \\
\hline 29 & GGAGCATCCATATTCTTT & GGTGTAGTTGTCTGGGTCT & 53 & 515 \\
\hline
\end{tabular}

the phylogenetic analyses have been frequently performed in several previous studies ${ }^{2,5-7}$. Recently, the complete pig mitogenome sequences and their phylogenetic relationships with other animal species were published $^{8}$. Fang and Andersson ${ }^{9}$ reported the haplotypes of European and Asian pig groups using the hypervariable control region sequence in more than 1500 mtDNA samples. Hongo et al. ${ }^{10}$ researched mtDNA sequences of 30 Vietnamese pigs and compared them with 61 other pig haplotypes. Their results showed that the Vietnamese pigs had a genetic relationship to the Ryukyu wild boar and other domestic pigs belonging to East Asia. Previous studies reported the shortest genetic distance between the indigenous pigs of Vietnam (e.g. I pig ${ }^{11}$, Huong pig $^{12}$, Muong Khuong pig ${ }^{13}$ and Ha Lang pig ${ }^{14}$ ) and Asian pig breeds. Qu et al. ${ }^{15}$ sequenced the D-loop region from 102 Yunnan indigenous pigs and indicated low genetic diversity between this breed and randomly bred pig breeds. Another researcher, Kim et al. ${ }^{16}$ also determined phylogenetic relationships using the D-loop region variation and the distinction time between Asian and European groups using average pairwise distance method.

Vietnam is part of mainland Southeast Asia. However, limited studies of mtDNA indicate the phylogenetic rela- tionship between the Vietnamese indigenous pig breeds and Asian pigs. The origin of pig breeds has especially been unknown. In previous studies, scientists have focused on evaluating the process of growth and development, namely the indices of growth, height, feed consumption, physiological indicators, fertility capacities in I and Mong Cai pig breeds ${ }^{17,18}$. While we were carrying out this research independently, $\operatorname{Tran}^{19}$ announced the mtDNA sequence of the Mong Cai pig, but there was not much genetic information about the pig genome given in that study. Here we report more detailed information about the gene organization and phylogenetics of the Mong Cai pig mitogenome. This study has also provided the relationship of domestic Mong Cai pig breed with other pig breeds in Asian and European regions and analysed the genetic origin. The added information on pig genetics is important for the livestock genetic diversity conservation and application programmes in Vietnam.

Mong Cai pig samples were collected in the Trang Due Breeding Centre, JSC Agricultural Investment and Development (Hai Phong, Vietnam) according to the management guidelines of the Vietnam National Institute of Animal Sciences. Genomic DNA was isolated from five millilitres blood of jugular vein samples using 
GeneJET $^{\mathrm{TM}}$ Whole Blood Genomic DNA Kit (Thermo Fisher, USA). The DNA final concentration was adjusted to $20 \mathrm{ng} / \mathrm{ml}$.

The complete mitogenome of Mong Cai pig was amplified by PCR method with fragment generated primer pairs (Table 1). All PCRs were conducted in Eppendorf Mastercycler Gradient. A volume of $50 \mu \mathrm{l}$ reaction mix containing $2 \mu \mathrm{l}$ of genomic DNA was used for PCR that was performed following our previous study protocols ${ }^{11-14}$. Five $\mu l$ of PCR products were visualized on $1 \%$ TBE agarose gel electrophoresis and ethidium bromide stained and then stored at $4^{\circ} \mathrm{C}$. Corrected size PCR products were prepared for sequencing using GeneJET ${ }^{\mathrm{TM}}$ PCR Purification Kit (Thermo Fisher, USA), according to the manufacturer's recommendations.

The purified products were sequenced according to dideoxynucleotide chain termination method ${ }^{20}$ using the ABI Big Dye Terminator v 3.1 Sequencing Standard Kit (Applied Biosystems, Foster City, CA) and performed on each template on the automated ABI 3500 Genetic Analyser (Applied Biosystems), following the manufacturer's protocol.

The complete mitogenome was assembled using DNA Dragon software. Gene annotation was performed by MITOS and DOGMA software. MITOS software also predicted the putative secondary structures of transfer RNA genes. Gene circular structure of mitochondria was built using GenomeVx. MUSCLE alignment method in MEGA6 was used to align sequences of Mong Cai pig and other references. The best Bayesian tree topology was calculated in BEAST software and Figure Tree software was used to build the phylogenetic tree.

The formation of Mong Cai pig's mtDNA showed a closed circular double helix DNA sizing approximately

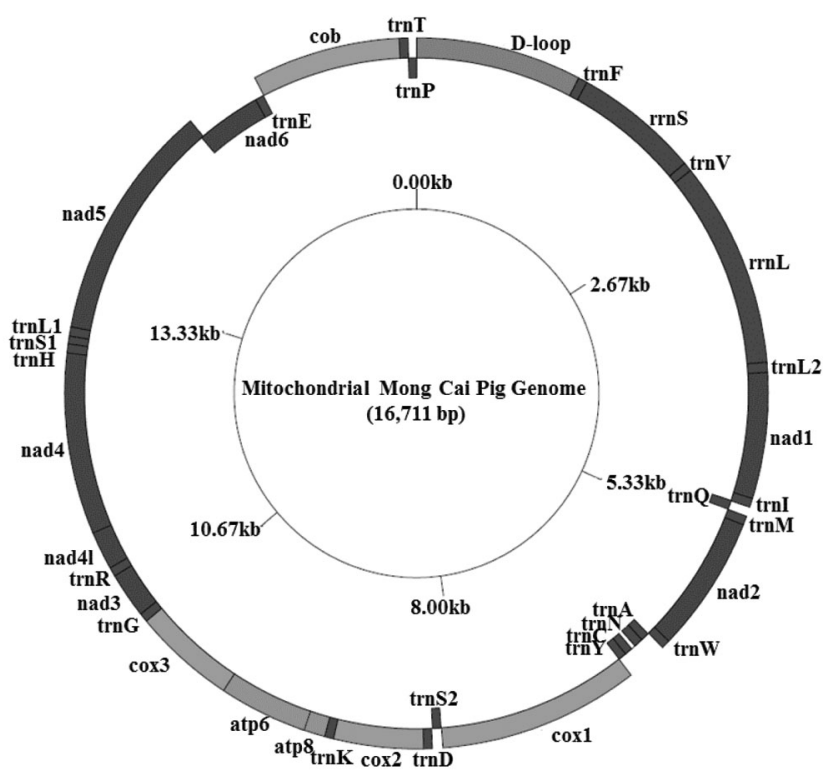

Figure 1. The circular map of the mtDNA of Mong Cai pig (GenomeVx).
16,711 bp, encoding 2 rRNAs, 22 tRNAs and 13 hydrophobic polypeptides (Figure 1). There were 11 noncoding regions (59 bp) that were dispersed over the whole $\mathrm{mt}$ genome, ranging from 1 to $32 \mathrm{bp}$, and the largest of these locations was between tRNA Cys and tRNA Tyr (32 bp). Mong Cai mtDNA was encoded for 3794 amino acids, and the most frequent codons were Methionine (ATG and ATA) and followed by GTG (Valine). Twelve protein-coding genes showed ATG (9 genes) and ATA (3 genes) start-codon, while only $N D 4 l$ showed a GTG startcodon. There were six TAA stop-codon genes and two TAG stop-codon genes. The incomplete stop-codon is performed with $\mathrm{T}$ - or TA- from the alignment of three genes (e.g. $C O X 2, N D 3$ and ND4 genes). Five gene positions showed overlaps - between tRNA Ile and tRNA Gln (3 bp), ATPase 8 and ATPase6 (43 bp), ND4 and tRNA His (7 bp), ND6 and tRNA Glu (14 bp), tRNA Glu and $C y t b$ (3 bp). In addition, all protein-coding genes except ND6 were located on $\mathrm{H}$ strand and exhibited a negative GC skew (from -0.20 to -0.56 ) and a positive AT skew (from 0.0 to 0.35 ).

Like other vertebrate animals, the Mong Cai pig had gene content and organization the same as those of Sus scrofa. Besides, codon usage and amino acid frequencies in the mt genome Mong Cai pig is similar to the other European and Asian pigs ${ }^{21-24}$. The base composition ratio of Mong Cai pig mt genome was 34.7\% (A), 25.8\% (T), $13.3 \%(\mathrm{G})$ and $26.2 \%(\mathrm{C})$. The nucleotide content of the entire $\mathrm{mt}$ genome sequence of Mong Cai pig is biased toward $\mathrm{A}+\mathrm{T}$ rich $(60.5 \%)$ that may be affected on the start of replication and transcription, in accordance with $\mathrm{mt}$ genomes of other Asia $\mathrm{pigs}^{22}$. In addition, the $\mathrm{mt}$ genome of Mong Cai pig has shown 16 intergenic regions, length ranging from 1 to $43 \mathrm{bp}$. The structure of genes in Mong Cai mtDNA was also the same as other vertebrates.

The non-coding control region of Mong Cai pig was of length $1275 \mathrm{bp}$ and contained essential transcription and replication elements ${ }^{25}$. There were 18 repeat regions $\left(5^{\prime}-\right.$ tacacgtgcg) in the sequence. This number showed a significant difference between the Mong Cai and other breeds such as Duroc (10 repeats), Landrace (13 repeats), Largewhite (6 repeats), Lanyu ( 25 repeats), Japanese wild boar (1 repeat) and Ryukyu wild boar (1 repeat) respectively.

As seen in almost all other Sus scrofa mitochondrial genome, Mong Cai pig exhibited 22 tRNA genes with length ranging from 59 to $75 \mathrm{bp}$. The cloverleaf shape of secondary structure in 21 tRNA has predicted a DHU arm with $4-8$ bp and DHU loop with $3-10$ bp in length, 8$10 \mathrm{bp}$ and 5-9 bp in T $\psi \mathrm{C}$ arm and $\mathrm{T} \psi \mathrm{C}$ loop respectively (Figure 2). In particular, tRNA Serl lacked the DHU arm and loop of the cloverleaf structure and only appeared in the $\mathrm{T} \psi \mathrm{C}$ arm and loop with $59 \mathrm{bp}$ in length, shorter than any known annotated tRNA in Mong Cai pig mt genome.

We have analysed the phylogenetic relationship of Mong Cai pig and other pigs by complete mtDNA 

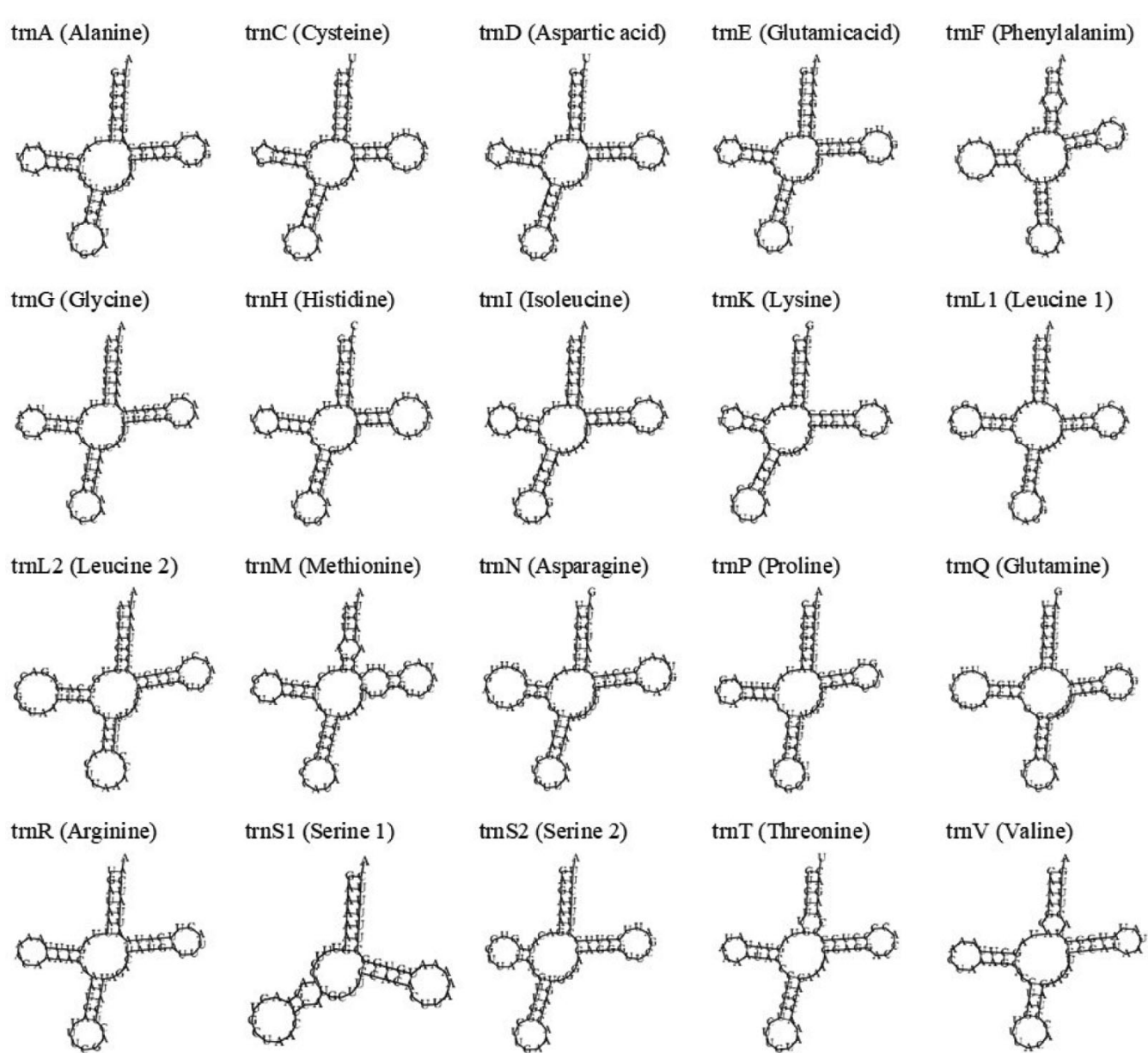

$\operatorname{trnS1}$ (Serine 1)
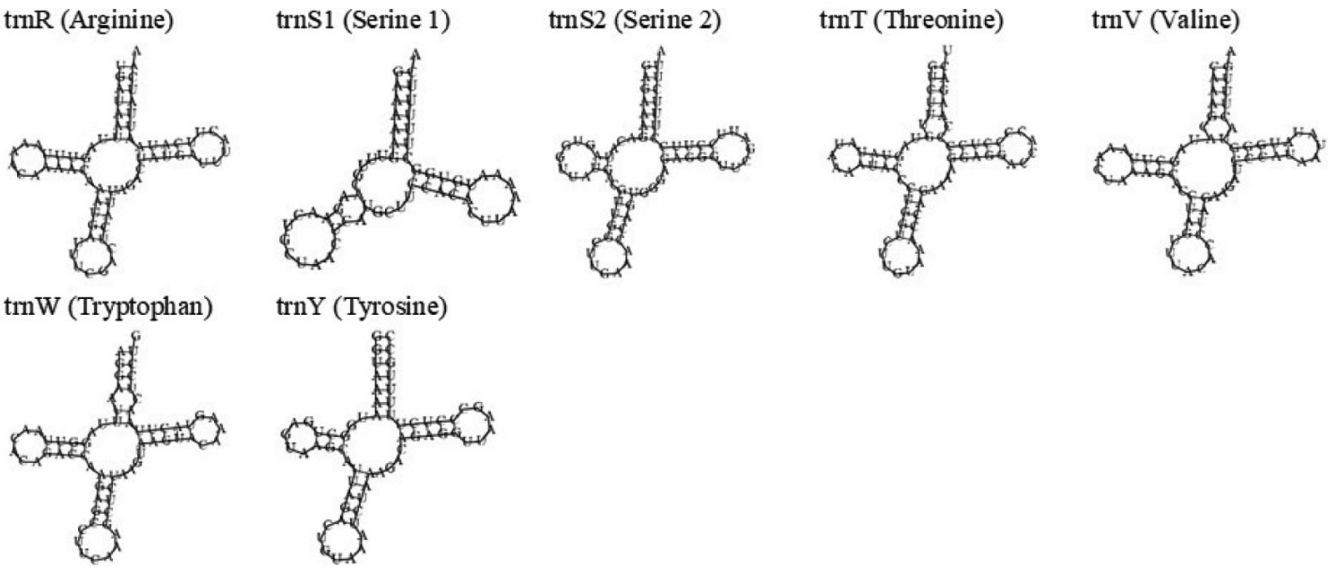

Figure 2. The clover leaf secondary structure of 22 tRNAs predicted in the mtDNA of Mong Cai pig (MITOS and DOGMA).

sequences (Figure 3). The results showed two large clusters, including wild boars and local breeds in Europe and Asia regions. In the phylogenetic tree, Vietnamese breeds (e.g. Mong Cai, Huong, Ha Lang, Muong Khuong and I pig) joined the Asian clade. For instance, the indigenous I breed had the closest genetic relationship with Banna mini - a Mekong region pig breed. While Huong, Ha Lang and Mong Cai pig breeds were close to Lantang - a South China region pig breed, Muong Khuong pig breed was close to Bihu breed from the region in central China. Genetic distance analysis among the pig breeds showed that Mong Cai pig had the largest genetic distance with the wild boar (WB)-Malaysia pig (0.0376), Lanyu pig (0.0256), European pigs (0.0158) and the shortest genetic distance with Lantang pig (0.0003).
In the previous studies, the mitochondrial genome analyses indicated a difference in the origin of pig breeds in European and Asian areas and accepted the hypothesis on separated origins of these native pig populations ${ }^{26,27}$. Also, Berkshire pigs are related to Asia breeds ${ }^{16,28,29}$. In addition, the studies on the morphological characteristics in Mong Cai pig and Lantang pig also showed the similarity in body conformation and colour characteristics. They are all small to medium in body size with small black heads with upright ears. There are two white bands running around the abdomen and the shoulder, adding a large black circle in the middle to create a black saddle. In addition, the black patches are also found in other places on the body ${ }^{30}$. We hypothesized that for thousands of years, the locals in the boundary areas between Mong Cai town, Quang Ninh province, Vietnam and 


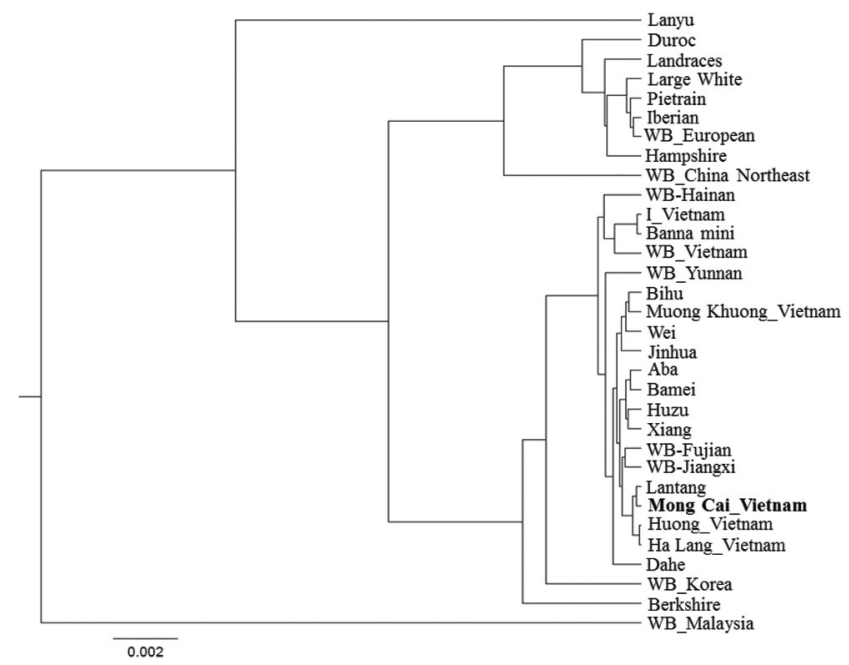

Figure 3. The phylogenetic tree between Mong Cai pig and other pig breeds using mitogenome sequences (BEAST and figure tree).

Guangdong province, South China have established a special trade model to exchange and sell goods in the border area of both countries. Even the pig breeds such as the indigenous Guangdong pigs (Lantang breeds) have also been traded in both areas and gradually contributed to the development of Vietnamese domestic pig breeds ${ }^{31}$. However, this still does not provide sufficient evidence to confirm the common origin of Mong Cai and Lantang breeds when maker genes were not used in this study. The results also indicated that the Mong Cai pig was found to be genetically close to other domestic pigs of China in the Southern region, Huang He and Yangtze River, besides the Lantang pig. This result was different from other previous studies about the Asian domestic pig population that confirmed their origin from multiple sources in $\mathrm{Asia}^{32,33}$. Therefore, further studies on genetic indicator are required for accurate answers on the origin of Vietnamese indigenous pig breeds, and the relationship between them and the other Asian pigs.

1. Nguyen, V. T., Tran, D. M. and Vo, T. H., The pigs in Vietnam Agriculture Publishing House, Hanoi, Vietnam (in Vietnamese), 2005 .

2. Watanabe, T., Hayashi, Y., Ogasawara, N. and Tomoita, T., Polymorphism of mitochondrial DNA in pigs based on restriction endonuclease cleavage patterns. Biochem. Genet., 1985, 23, 105-13.

3. Avise, J. C., Mitochondrial DNA and the evolutionary genetics of higher animals. Philos. Trans. R. Soc. B: Biol. Sci., 1986, 312, $325-342$.

4. Huo, J. H. et al., Population phylogenomic analysis and origin of mitochondrial DNA in Chinese domestic pig. Mitochondrial DNA A DNA Mapp Seq. Anal., 2016, 27, 892-895.

5. Lan, H. and Shi, L., The origin and genetic differentiation of native breeds of pigs in southwest China: an approach from mitochondrial DNA polymorphism. Biochem. Genet., 1993, 31, 51-60.

6. Huang, Y. F., Shi, X. W. and Zhang, Y. P., Mitochondrial genetic variation in Chinese pigs and wild boars. Biochem. Genet., 1999, 37, 335-343.
7. Gongora, J. et al., Phylogenetic relationships of Australian and New Zealand feral pigs assessed by mitochondrial control region sequence and nuclear GPIP genotype. Mol. Phylogenet. Evol., 2004, 33, 339-348.

8. Ursing, B. M. and Arnason, U., The complete mitochondrial DNA sequence of the pig (Sus scrofa). J. Mol. Evol., 1998, 47, 302-306.

9. Fang, M. and Andersson, L., Mitochondrial diversity in European and Chinese pigs is consistent with population expansions that occurred prior to domestication. Proc. R. Soc. B: Biol. Sci., 2006, 273, 1803-1810.

10. Hongo, H. et al., Variation in mitochondrial DNA of Vietnamese pigs: relationships with Asian domestic pigs and Ryukyu wild boars. Zool. Sci., 2002, 19, 1329-1335.

11. Nguyen, H. D., Bui, T. A., Nguyen, P. T., Kim, O. T. P. and Vo, T. T. B., The complete mitochondrial genome sequence of the indigenous I pig (Sus scrofa) in Vietnam. Asian-Australas J. Anim. Sci., 2017, 30, 930-937.

12. Vo, T. B. T., Nguyen, D. H., Bui, T. A., Nghiem, N. M. and Jeung, E. B., Phylogenomic analysis of mitochondrial DNA in the Huong pig: an indigenous pig of Vietnam. Global J. Anim. Breed. Genet., 2017, 5, 389-396.

13. Nguyen, H. D., Pham, T. L., Bui, T. A., Nghiem, N. M. and Vo, T. B. T., The complete sequence of mitochondrial genome of Muong Khuong Pig (Sus Scrofa). Int. J. Res. Stud. Biosci., 2017, 5, 1-3.

14. Bui, T. A., Nguyen, D. H. and Vo, T. B. T., Complete mitochondrial genome sequence and phylogenetic status of Halang pig (Sus scrofa). Asian J. Biol., 2018, 6, 1-8.

15. Qu, K. X., Wu, G. S., Gou, X., Yan, D. W., Lian, L. S., Baig, M. and Zhang, Y. P., Genetic differentiations between randomly and selectively bred pig populations in Yunnan, China. Zool. Res., 2011, 32, 255-261.

16. Kim, K. I., Lee, J. H., Li, K., Zhang, Y. P., Lee, S. S., Gongora, J. and Moran, C., Phylogenetic relationships of Asian and European pig breeds determined by mitochondrial DNA D-loop sequence polymorphism. Anim. Genet., 2002, 33, 19-25.

17. Nguyen, V. T. and Dinh, H. L., Some genetic characteristics in productivity of the I and Mong Cai pigs (Sus vittatus). The initial results in the conservation of livestock genetic resources in Vietnam. Agriculture Publishing House, Hanoi, Vietnam (in Vietnamese), 1994.

18. Le, T. T. and Bui, K. H., Survey some indicators of growth, sexual maturity, fertility of the Ban and Mong Cai pigs that raised in the upland farmers of Yen Chau district, Son La province. J. Anim. Sci. Biotechnol., 2005, 7, 4-7 (in Vietnamese).

19. Tran, T. T. N. et al., The complete mitochondrial genome of Mong Cai pig (Sus scrofa) in Vietnam. Mitochondrial DNA B, 2016, 1, 226-227.

20. Sanger, F., Nicklen, S. and Coulson, A. R., DNA sequencing with chain-terminating inhibitors. Proc. Natl. Acad. Sci. USA, 1977, 74, 5463-5467.

21. Ran, M. L., Liu, Z., Yang, A. Q., Li, Z. and Chen, B., The complete sequence of the mitochondrial genome of Lantang pig (Sus scrofa). Mitochondrial DNA, 2016, 27, 1376-1377.

22. Wang, L. Y., Chai, Y. L. and Ma, H. M., The complete sequence of the mitochondrial genome of Duroc pig (Sus scrofa). Mitochondrial DNA, 2016, 27, 3-4.

23. Xu, D., Yang, H. and Ma, H., The complete mitochondrial genome of the Yorkshire pig (Sus scrofa). Mitochondrial DNA, 2016, 27, 641-642.

24. Chai, Y. L., Xu, D. and Ma, H. M., The complete sequence of mitochondrial genome of Wuzhishan pig (Sus scrofa). Mitochondrial DNA, 2016, 27, 94-95.

25. Levin, B. C., Cheng, H. and Reeder, D. J., A human mitochondrial DNA standard reference material for quality control in forensic identification, medical diagnosis, and mutation detection. Genomics, 1999, 55, 135-146. 
26. Fan, B. et al., Genetic variation analysis within and among Chinese indigenous swine populations using microsatellite markers. Anim. Genet., 2002, 33, 422-427.

27. Kijas, J. M. and Andersson, L., A phylogenetic study of the origin of the domestic pig estimated from the near-complete mtDNA genome. J. Mol. Evol., 2001, 52, 302-308.

28. Yu, G., Xiang, H., Wang, J. and Zhao, X., The phylogenetic status of typical Chinese native pigs: analyzed by Asian and European pig mitochondrial genome sequences. J. Anim. Sci. Biotechnol., 2013, 4, 9.

29. Li, K. Y., Li, K. T., Cheng, C. C., Chen, C. H., Hung, C. Y. and Ju, Y. T., A genetic analysis of taoyuan pig and its phylogenetic relationship to eurasian pig breeds. Asian-Australas. J. Anim. Sci., 2015, 28, 457-466.

30. Rothschild, M. F. and Ruvinsky, A., The Genetics of the Pig, CPI Antony Rowe, Chippenham, London, UK, 2011, 2nd edn.

31. Tran, V. P., Husbandry Techniques of the Breeding Snows, Labour Publishing House, Hanoi, Vietnam (in Vietnamese), 2005.

32. Luetkemeier, E. S., Sodhi, M., Schook, L. B. and Malhi, R. S., Multiple Asian pig origins revealed through genomic analyses. Mol. Phylogenet. Evol., 2010, 54, 680-686.

33. Megens, H. J., Crooijmans, R. P., San Cristobal, M., Hui, X., Li, N. and Groenen, M. A., Biodiversity of pig breeds from China and Europe estimated from pooled DNA samples: differences in microsatellite variation between two areas of domestication. Genet. Sel. Evol., 2008, 40, 103-128.

ACKNOWLEDGEMENT. This research was funded by the Vietnam National Foundation for Science and Technology Development (NAFOSTED) under grant number: 106-NN.05-2014.66.

\section{Early Oligocene (Rupelian) dinoflagellate cysts and calcareous nannofossils from Lumpy Clay Member of Maniyara Fort Formation, Kutch, Gujarat, India}

\author{
Poonam Verma* and Abha Singh \\ Birbal Sahni Institute of Palaeosciences, 53-University Road, \\ Lucknow 226 007, India
}

The Palaeogene succession of Kutch, Gujarat exhibits huge shallow marine carbonate deposits of Middle Eocene and Oligocene ages. These deposits were mainly dated on the basis of larger benthic foraminifers. The paucity of foraminifers in the intermittent units of the succession resulted in discrepancy in

*For correspondence. (e-mail: verma.poonam07@gmail.com) precise dating of these strata. Lumpy Clay Member of Maniyara Fort Formation is one such example. This is considered as unfossiliferous in terms of foraminifers and was dated on the basis of foraminiferal assemblages of underlying Basal and overlying Coral Limestone members. In the present study, palynological biostratigraphy is proposed for the Lumpy Clay Member exposed at Bermoti Village, in Kutch. On the basis of age-diagnostic calcareous nannofossil and dinoflagellate cyst assemblages, the studied succession has been dated as Middle Rupelian ( $31 \mathrm{Ma})$. The palynological data suggests a shallow marine neritic depositional setting, occasionally swept by open oceanic water.

Keywords: Calcareous nannofossils, dinoflagellate cysts, Kutch, Lumpy Clay Member, Maniyara Forth Formation, Rupelian.

DURING the Eocene-Oligocene transition, intense climatic and oceanographic changes occurred coupled with the first major continental-scale glaciation of Antarctica ${ }^{1,2}$. These complex series of events occurred over an extended period between $\sim 33.5$ and $34.0 \mathrm{Ma}$, causing environmental disturbances that led to a global biotic turnover seen in both terrestrial and marine records of shallow-water and deep-sea environments. Spanning this transition interval, many thick Cenozoic limestone deposits containing larger benthic foraminifers are common within the Indo-Pacific region ${ }^{3-6}$. However, due to lowered global sea level during the Eocene-Oligocene transition, many stratigraphic sections are incomplete, with hiatuses or unconformities. In India, the Amravati Formation of Cambay Basin ${ }^{7}$ and Fulra and Maniyara Fort formations of Kutch $\operatorname{Basin}^{8-10}$ are considered to be among the most complete sections with some hiatuses.

The Kutch sedimentary basin in the western continental margin of India is a peri-cratonic rift basin which archives almost complete sedimentary records from Middle Jurassic to the present, interrupted by several episodes of non-deposition. The nearly complete, richly fossiliferous and easily accessible outcrops of Cenozoic sediments exposed in the western part of the Kutch mainland extend offshore into the present-day continental shelf.

Particularly, the marine Oligocene outcrops in the western part of Kutch have been initially recognized under the Nari Series of Pakistan ${ }^{11,12}$. Later, Biswas and Raju $^{13}$, and Biswas ${ }^{14}$ designated the Oligocene strata of Kutch as the Maniyara Fort Formation (Table 1), exposed in a type section near Bermoti Village along the Bermoti River. The Maniyara Fort Formation consists of a succession of bedded, yellow to ochre-coloured foraminiferal limestone with a basal greyish-green glauconitic siltstone overlying the Middle Eocene Fulra Limestone. The formation is richly fossiliferous with a variety of echinoids, pelecypods, gastropods, corals, foraminifers and crabs. Nummulites fichteli and Miogypsinoides are the 